\title{
Development and Validation of First Derivative Spectrophotometric Method for Quantification of Darunavir in Tablets
}

\section{Josilene Chaves Ruela Corrêa ${ }^{1^{*}}$, Cristina Helena dos Reis Serra ${ }^{2}$ and Hérida Regina Nunes Salgado ${ }^{1}$}

${ }^{1}$ Drugs and Pharmaceuticals Quality Control Laboratory, School of Pharmaceutical Sciences, Univ Estadual Paulista, Rod. Araraquara-Jaú, km 1, 14801-902; Araraquara, Brazil.

${ }^{2}$ School of Pharmaceutical Sciences, University of São Paulo, São Paulo-SP, Brazil.

Authors' contributions

All authors have contributed equally for this article. All authors have read and approved the final manuscript.

Original Research Article

Received $9^{\text {th }}$ August 2013

Accepted $21^{\text {st }}$ October 2013

Published $30^{\text {th }}$ January 2014

\section{ABSTRACT}

Aims: Darunavir is widely used in HIVIAIDS therapy. It is a HIV protease inhibitor that has excellent efficacy against the virus. The aim of this study is to develop and validate an analytical method fast and free of interferences for determination of darunavir ethanolate as raw material and tablet dosage form.

Methodology: As the formulation excipients show high interference in darunavir determination by a direct UV absorption measurement a derivative spectrophotometry was applied. A selective, easy and fast method was achieved employing simple and cheap instrumentation by using first-order derivative spectrophotometry.

Results: The first-derivation of spectrum of the drug measured between 200 and $400 \mathrm{~nm}$ allowed identification of the analyte and showed absence of placebo interference. The assay was based on the absorbance at $276 \mathrm{~nm}$. The linear concentration range was established from 11 to $21 \mu \mathrm{g} / \mathrm{mL}$. The intra-day and inter-day precision expressed as RSD was $0.06 \%$ and $3.75 \%$ respectively with mean recovery of $99.84 \%$.

Conclusion: The proposed analytical method is able to quantify darunavir as raw material and tablets and can be used routinely by any laboratory applying a spectrophotometer 
with a derivative accessory. The great difference of the method proposed here is that it proves to be free of placebo interferences as well as simple, fast and low cost.

Keywords: HIVIAIDS; darunavir; pharmaceutical dosage form; analytical validation; derivative spectrophotometry.

\section{INTRODUCTION}

Darunavir is a HIV protease inhibitor and represents a great advantage in HIVIAIDS treatment since it has excellent efficacy against the virus [1].

Many studies have showed that darunavir has significantly improved virological and immunological outcomes compared with others Pls and it is generally well tolerated. Darunavir shows low bioavailability, around of $37 \%$, but when it is administered in combination with ritonavir, a potent inhibitor of CYP3A4, and food the bioavailability is increased to $82 \%$. The most important route of metabolism of darunavir is by cytochrome P450 (CYP450) enzymes, mainly CYP3A4, therefore, compounds that alter CYP3A4 activity and expression might influence darunavir concentrations [1].

Darunavir (Fig. 1) is marketed in ethanolate form under the brand name of Prezista ${ }^{\mathrm{TM}}$ and it is available in different dose strength such as $75,150,300,400$ and $600 \mathrm{mg}$. It is also is available as an oral suspension in which the darunavir dose is $100 \mathrm{mg} / \mathrm{mL}$. The dosage form used in this study was Prezista TM $300 \mathrm{mg}$ darunavir tablets. This dosage has the following composition: $325.24 \mathrm{mg}$ of darunavir ethanolate (equivalent to $300 \mathrm{mg}$ of darunavir) and the inactive ingredients (crospovidone, magnesium stearate, Opadry TM II White (partially hydrolyzed polyvinyl alcohol, titanium dioxide, macrogol and talc) and Prosolv ${ }^{\mathrm{TM}}$ (microcrystalline cellulose and colloidal silicon dioxide) [2].<smiles>CC(C)CN(C[C@H](O)[C@H](Cc1ccccc1)NC(=O)O[C@H]1CO[C@@H]2OCC[C@H]21)S(=O)(=O)c1ccc(N)cc1</smiles>

Fig. 1. Chemical structure of darunavir

To analyze the pharmaceutical active ingredient in a dosage form can be a challenge depending on the inactive ingredients used and the techniques and apparatus available. The interference of inactive ingredients over the measurements is something very common and in many cases the derivative spectrophotometry is a tool often applied to develop a fast and selective analytical method.

The aim of this work was to develop and validate a selective first derivative spectrophotometric method to determine darunavir ethanolate in raw material and tablets. 
Rocha \& Teixeira describes that the analytical applications of derivative spectrophotometry are based on the fact that the derived measurements are always proportional to the concentration of the analyte, which is shown by the differentiation of the Lambert-Beer law. Using spectral derivation it is possible to observe increased selectivity; sensitivity and improved detection limit [3].

As it was reported by Corrêa and coworkers in a review paper, there are some studies applying high performance liquid chromatography (HPLC) with ultraviolet detector or mass spectrometer for determination of darunavir in biological samples and tablets [4-9]. Patel and coworkers developed a HPLC method for the estimation of darunavir in tablet dosage form using a C18 column and the effluents were monitored at $267 \mathrm{~nm}$ [9]. Mane and colleagues also have developed a HPLC method for darunavir in tablets applying a C18 column and an UV detector at $264 \mathrm{~nm}$ [10]. A quantitative high performance thin layer chromatography (HPTLC) method for determination of darunavir was developed and validated by Patel and coworkers [7] and by Ramesh and coworkers [8]. The first authors used the wavelength $267 \mathrm{~nm}$ to detect the drug [11] and the second authors used reflectance scanning at $262 \mathrm{~nm}$ and mass spectra, $[\mathrm{M}+\mathrm{Na}]^{+}, \mathrm{m} / \mathrm{z} 569.80$, to detect the drug [12]. A spectrophotometry method had already been used to determine darunavir in tablets; it was developed by Reddy and Ramireddy [9]. The inconvenience of this method is the dependence of a previous reaction.

To determine darunavir in the presence of degradation products some analytical methods have been developed using HPLC with UV [2] and mass detection [14] Darunavir is not described in any pharmacopeia or official compendium. The method described here uses first-derivative spectrophotometry. It shows to be more specific than direct absorption measurement and faster than HPLC assay. The great difference of the method proposed here is that it proves to be free of placebo interferences as well as simple, fast and low cost.

\section{METHODOLOGY}

\subsection{Apparatus and Reagents}

A UV-Visible spectrophotometer (UV 1800, Shimadzu, Japan) and the software UV Probe was used for the assay. Hydrochloric acid, sodium acetate, potassium phosphate sodium hydroxide, and acetic acid (reagent grade) were used. Sample and standard solutions were filtered through a quantitative paper filter $(2 \mu$, JProlab, Brazil).

Darunavir chemical reference (assigned purity of 98\%) was obtained from Sequoia Research (Pangbourne, United Kingdom), darunavir raw material was extracted from Prezista $^{\mathrm{TM}}$ tablets by ethanol extraction using an adaptation of the method described by Berginc and coworkers [15]. The purity of extracted darunavir was confirmed by HPLC analysis at $267 \mathrm{~nm}$ and by infrared spectroscopy. The darunavir peak surface represented $96.6 \%$ of the total chromatogram surface area and by infrared spectroscopy darunavir standard and extracted sample have showed the same characteristic peaks. It was standardized against darunavir chemical reference which contained $94 \%$ of darunavir. Darunavir ethanolate tablets $300 \mathrm{mg}$ (Prezista ${ }^{\mathrm{TM}}$ ) were purchased from local market. The placebo of darunavir tablets was obtained as result of the extraction from Prezista ${ }^{\mathrm{TM}}$. The details of this extraction was given in a previous publication [2]. 


\subsection{Standard Solutions Preparation}

Darunavir standard stock solution was prepared by dissolving $6.5 \mathrm{mg}$ of standard accurately weighed in $200 \mathrm{~mL}$ volumetric flask. Darunavir was solubilized with $40 \mathrm{~mL}$ methanol and $100 \mathrm{~mL}$ water. It was kept in ultrasonic bath for $10 \mathrm{~min}$, and the volume was making up to volume with water. Further diluting to volume with water six final concentrations were obtained: $11,13,15,17,19$ and $21 \mu \mathrm{g} / \mathrm{mL}$.

\subsection{Sample Preparation}

To prepare the sample solution, 20 darunavir tablets were weighed, powdered and its powder mixed making a pool. A quantity equivalent to $6.5 \mathrm{mg}$ of darunavir was transferred into a $200 \mathrm{~mL}$ volumetric flask with $40 \mathrm{~mL}$ methanol and $100 \mathrm{~mL}$ water, kept in ultrasonic bath for 10 minutes, and the remaining volume was made up with water. The working concentration, $15 \mu \mathrm{g} / \mathrm{mL}$, was achieved by dilution using water to fill the volumetric flask. Placebo solution was prepared at the same procedure.

\subsection{Instrumentation}

The spectrophotometer was programmed to generate the zero order and first order derivative scan between 200 and $400 \mathrm{~nm}$, using its medium scan speed to acquire spectra signals, the sampling interval was 0.2 , slit width was 1.0 , delta lambda was 2.0 and scaling factor was 1.0. Smoothing was not used. The quantitation involved measurement of amplitude of the zero order peaks at $267 \mathrm{~nm}$ and first-derivative valley at $276 \mathrm{~nm}$.

\section{RESULTS AND DISCUSSION}

\subsection{Analytical Method Development}

The selectivity of the derivative method is one of the most important characteristics compared to zero order spectrophotometry and it shows to be effective in darunavir case which suffers placebo interference but using the first order derivative method the interference has disappeared.

The procedure performed to reach a selective spectrophotometric method was conducted using darunavir raw material, tablets and placebo. Sample solutions were prepared in different solutions as hydrochloric acid $0.1 \mathrm{M}$, acetate buffer $(\mathrm{pH} 4.5)$, phosphate buffer $(\mathrm{pH}$ 6.8 ) and water. The darunavir absorption was measured at the range of $200-400 \mathrm{~nm}$ and the derivation of the absorption curve was calculated by the software (Figs. 2 and 3 ). The percentage of placebo's interference was calculated using the zero order and the first order derivation of the absorption curve. As the order of derivative has to be carefully selected, since there is usually an increased noise level with increasing derivation order, the first order was tried first. The next order was not tried since good results were found using the first order derivation. 

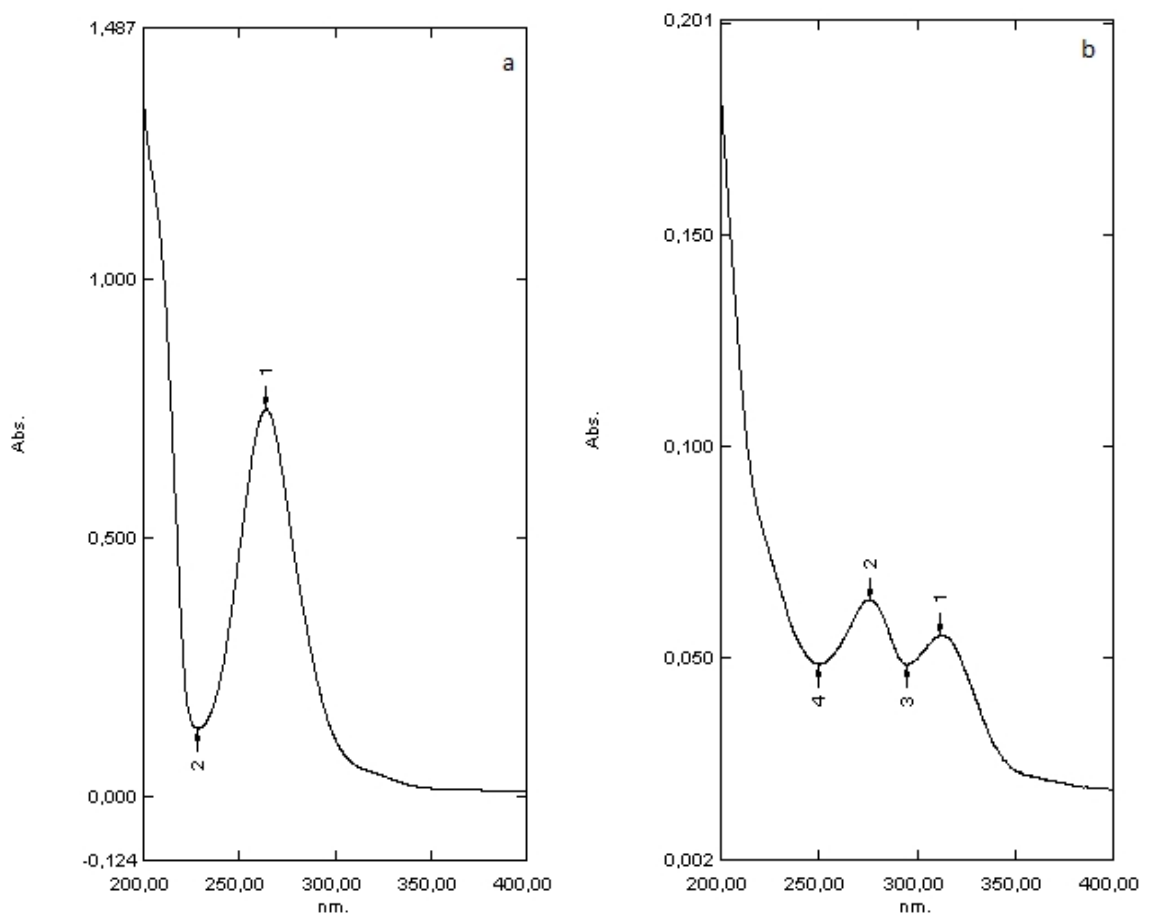

Fig. 2. Zero order UV absorption spectrum of (a) darunavir tablets, and (b) placebo at $15 \mu \mathrm{g} / \mathrm{mL}$.
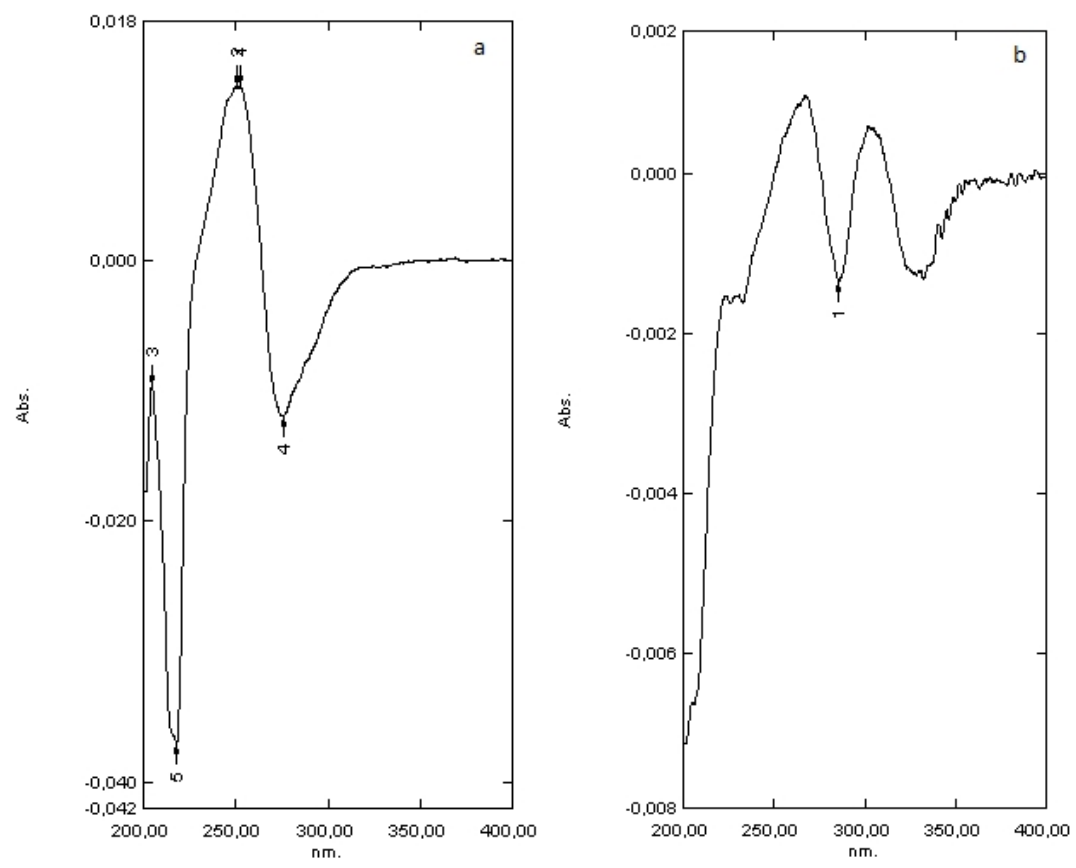

Fig. 3. First order derivative UV spectrum of (a) darunavir tablets, and (b) placebo at $15 \mu \mathrm{g} / \mathrm{mL}$. 
Table 1. Placebo interference at darunavir determination

\begin{tabular}{lll}
\hline Media & Interference (\%) \\
\cline { 2 - 3 } & $\begin{array}{l}\text { Zero order } \\
\mathbf{( 2 6 7} \mathbf{~ n m ) ~}\end{array}$ & $\begin{array}{l}\text { First order } \\
\mathbf{( 2 7 6 ~} \mathbf{~ m})\end{array}$ \\
\hline Water $(20 \%$ of $\mathrm{MeOH})$ & 7.92 & 0 \\
Hydrochloric acid $0.1 \mathrm{M}$ & 5.70 & 0 \\
Acetate buffer, $\mathrm{pH} 4.5(20 \%$ of $\mathrm{MeOH})$ & 3.25 & 0 \\
Phosphate buffer, $\mathrm{pH} 6.8(20 \%$ of $\mathrm{MeOH})$ & 1.35 & 0 \\
\hline
\end{tabular}

All samples were evaluated by first derivative order in four different solution media. The table 1 shows that the interference of placebo disappears when the first order is applied. The wavelength used was $276 \mathrm{~nm}$ because, as shown by figure 2, it is an intense, better characterized valley. The increased selectivity observed in the derivative spectroscopy is based on the relationship between the amplitude of the derivative absorbance and the wavelength which is inversely proportional to the bandwidth of the ordinary spectrum [16].

Darunavir was determined in tablets in triplicate using the different solubilization media and the most precise result was found when the aqueous solution of methanol was applied. The aqueous solution of methanol (20\% of methanol) was chosen to solubilization of the samples.

\subsection{Method Validation}

The specificity of the method was evaluated by comparison of absorbance spectra of darunavir raw material, tablets and placebo samples. The absence of interfering compounds was verified by comparison of the first-derivative spectrum of placebo, raw material and product samples. The method was validated in agreement with $\mathrm{ICH}$ guide lines [17].

After parameters of the method were established the method was validated. The linearity was assessed with concentrations 11 to $21 \mu \mathrm{g} / \mathrm{mL}$ as an effort to work within the range where the linearity is usually observed ( 0.2 to 0.8 absorbance units, $A U)$. Thus the selected working concentration was $15 \mu \mathrm{g} / \mathrm{mL}$. The linearity was evaluated by the least square regression method. The method showed good linearity over the concentration range. The coefficient of determination was equal to 0.997 and the regression equation was $y=0.017 x-$ 0.0039 ( $y$, amplitude of first-derivative spectrum; $x$, concentration $\mu \mathrm{g} / \mathrm{mL}$ ) (Table 2). The validity of the method was verified by means of the analysis of variance (ANOVA). According to ANOVA there is linear regression in the tested concentration range (Fcalculated $>$ Fcritical; $P=0.05$ ) and there is no deviation from linearity (Fcalculated < Fcritical; $P=0.05$ ).

The samples were analyzed in triplicate in all concentration range at the same day (withinday precision) and also at low, medium (working) and high concentration on different days (between-day precision). The method showed good precision with relative standard deviation (RSD) of 0.06 and 3.75, respectively for within-day and between day assays (Table 2).

The accuracy of the method was determined by the mean recovery. Placebo samples were spiked with darunavir raw material and solutions at the six concentrations of linear range 
were performed in triplicate. The mean result was $99.84 \%$ (Tables 2 and 3 ) indicating an agreement between the true value and the value found.

The limits of detection and quantification were determined based on the standard deviation of the response and the slope, based on the calibration curve. This way to calculate the limits is recommended and explained by the $\mathrm{ICH}$ guideline [17]. They were calculated as 3 $\sigma / S$ and $10 \sigma / S$, respectively, where $S$ is the slope of the calibration curve and $\sigma$ is the standard deviation of $y$-intercept of regression equation. The limits of detection and quantification were 0.09 and $0.30 \mu \mathrm{g} / \mathrm{mL}$, respectively (Table 2 ).

Table 2. Validation parameters

\begin{tabular}{ll}
\hline Parameters & Results \\
\hline Useful concentration, $\mu \mathrm{g} / \mathrm{mL}$ & 15 \\
Analytical curve & $0.0038 \mathrm{X}-0.0017$ \\
Determination coefficient $\left(\mathrm{r}^{2}\right)$ & 0.997 \\
R.S.D. within-day $(\%)$ & 0.06 \\
R.S.D. between-day (\%) & 3.75 \\
Recovery $(\%)$ & 99.84 \\
RSD of recovery $(\%)$ & 1.52 \\
Detection limit ${ }^{\mathrm{a}}, \mu \mathrm{g} / \mathrm{mL}$ & 0.09 \\
Quantification limit ${ }^{\mathrm{b}}, \mu \mathrm{g} / \mathrm{mL}$ & 0.30 \\
\hline
\end{tabular}

Table 3. Recovery data

\begin{tabular}{ll}
\hline $\begin{array}{l}\text { Added amount } \\
(\mu \mathrm{g} / \mathrm{mL})\end{array}$ & Recovery (\%) \\
\hline 11.0 & 98.79 \\
13.0 & 98.54 \\
15.0 & 100.25 \\
17.0 & 99.28 \\
19.0 & 100.09 \\
21.0 & 102.08 \\
\hline
\end{tabular}

To evaluate the robustness of the proposed method low and deliberate changes were made on the time of ultrasonic bath. Sample and standard solutions were submitted during nine, ten (standardized condition) and eleven minutes. The interference of these changes over assay test was monitored (Table 4).

Table 4. Robustness data

\begin{tabular}{ll}
\hline Time at ultrasonic bath $(\boldsymbol{m i n})$ & Assay $(\%)$ \\
\hline 9.0 & 97.68 \\
10.0 & 96.64 \\
11.0 & 96.13 \\
\hline
\end{tabular}

A method is said to be robust when the alterations produce no significant changes in the results. The results for the robustness test show values considerably low and not significant in routine analyses. 


\section{CONCLUSION}

This study describes a useful, rapid and reliable method for darunavir assay. The proposed method was used successfully to determine darunavir raw material and tablets. The results of the validation studies show that the spectrophotometric method is selective, accurate and has significant linearity and precision without any interference from the excipient.

The new UV derivative method allows a rapid and economical quantitation of darunavir raw material and tablets without any time-consuming sample preparation. Moreover, the spectrophotometric methods involve simpler and cheaper instrumentation compared to other instrumental techniques, as for instance, chromatographic methods. It also does not depend on previous reaction for the measurements of drug concentration as a spectrophotometric method previously published and cited in this paper. The method proposed can be easily applied in routine practice by any laboratory possessing a spectrophotometer with a derivative accessory.

\section{ACKNOWLEDGEMENTS}

The authors thank to PADC-UNESP, FUNDUNESP, CNPq and FAPESP for the financial support.

\section{CONSENT}

It is not applicable.

\section{ETHICAL APPROVAL}

It is not applicable.

\section{COMPETING INTERESTS}

The authors do not have any direct financial relation with the commercial identities mentioned in this paper. There is no conflict of interest for any of the authors.

\section{REFERENCES}

1. Corrêa JCR, D'Arcy DM, Serra CHR, Salgado HRN. Darunavir: a critical review of its properties, use and drug interactions. Pharmacology. 2012;90:102-109.

2. Corrêa JCR, Serra CHR, Salgado HRN. Stability Study of Darunavir Ethanolate Tablets Applying a New Stability-Indicating HPLC Method. Chromatog. Res. Int. 2013; article ID 834173. Available at: http://dx.doi.org/10.1155/2013/834173.

3. Rocha FRP, Teixeira LSG. Strategies to increase sensitivity in UV-VIS spectrophotometry. Quim. Nova. 2004;27(5):807.

4. Corrêa JCR, D'Arcy DM, Serra CHR, Salgado HRN. A Critical Review of Properties of Darunavir and Analytical Methods for its Determination. Crit. Rev. Anal. Chem. 2013. (In press). 
5. D'avolio A, Simiele M, Siccardi M, Baietto L, Sciandra M, Oddone V, Stefani FR, Agati S, Cusato J, Bonora S, Di Perri G. A HPLC-MS method for the simultaneous quantification of fourteen antiretroviral agents in peripheral blood mononuclear cell of HIV infected patients optimized using medium corpuscular volume evaluation. J. Pharm.Biomed. Anal. 2011;54:779-788.

6. Curran A, Gutirerrez M, Deig E, Mateo G, Lopez RM, Imaz A, Crespo M, Ocana I, Domingo P, Ribera E. Efficacy, safety and pharmacokinetics of 900/100 mg of darunavir/ritonavir once daily in treatment-experienced patients. J. Antimicrob. Chemother. 2010;65:2195-2203.

7. Garcia SP, Tunica DG, Serra MB. Development and assessment of a method for the determination of darunavir in plasma by LC-MS/MS. Rev. Laboratorio Clínico. 2011;4:127-133.

8. Else L, Watson V, Tjia J, Hughes A, Siccardi M, Khoo S, Back D. Validation of a rapid and sensitive high-performance liquid chromatography-tandem mass spectrometry (HPLC-MS/MS) assay for the simultaneous determination of existing and new antiretroviral compounds. J. Chromatogr. B. 2010;878:1455-1465.

9. Patel BN, Suhagia BN, Patel CN. RP-HPLC method development and validation for estimation of darunavir ethanolate in tablet dosage form. Int. J. Pharm. Pharm. Sci. 2012;4(3):270-273.

10. Mane PM, Pranali J. Gaikawad PJ, Patil AV, Mogale AS. RP-HPLC Method for Determination of Darunavir in Bulk and Pharmaceutical. Int. J. Pharm. Sci. Rev. 2013;21(2):20-23.

11. Patel BN, Suhagia BN, Patel CN, Panchal HJ. A simple and sensitive HPTLC method for quantitative analysis of darunavir ethanolate tablets. J. Plan. Chromatog. 2011;24(3):232-235.

12. Ramesh B, Ramakrishna S, Reddy RKK, Babu KH, Sarma VUM, Devi PS. HPTLC method for determination of darunavir in rat plasma and its application in pharmacokinetic studies. J. Liq. Chrom. Relat. Tech. 2013;36(2):167-179.

13. Reddy MP, Ramireddy N. Spectrophotometric estimation of darunavir in bulk and pharmaceutical formulations. Int. J. Chem. Sci. 2013;11(1):614-618.

14. Rao RN, Ramachandra B, Santhakumar K. RP-HPLC separation and characterization of unknown impurities of a novel HIV-protease inhibitor Darunavir by ESI-MS and 2D NMR spectroscopy. J. Pharm. Biomed. Anal. 2013;75:186-191.

15. Berginc K, Trdan T, Trontelj J, Kristl A. HIV Protease Inhibitors: Garlic Supplements and First-pass Intestinal Metabolism Impact on the Therapeutic Efficacy. Biopharm. Drug Dispos. 2010;31:495-505.

16. Correa JCR, Reichman C, Vianna-Soares CD, Salgado HRN. Performance characteristics of high performance liquid chromatography, first order derivative UV spectrophotometry and bioassay for fluconazole determination in capsules. Quim. Nova. 2012;35(3):530-534.

17. $\mathrm{ICH}$, Validation of Analytical Procedures: Text and Methodology, Harmonized Tripartite Guideline Q2 (R1), 2005.

(c) 2014 Corrêa et al.; This is an Open Access article distributed under the terms of the Creative Commons Attribution License (http://creativecommons.org/licenses/by/3.0), which permits unrestricted use, distribution, and reproduction in any medium, provided the original work is properly cited.

Peer-review history:

The peer review history for this paper can be accessed here: http://www.sciencedomain.org/review-history.php?iid=407\&id=14\&aid=3487 